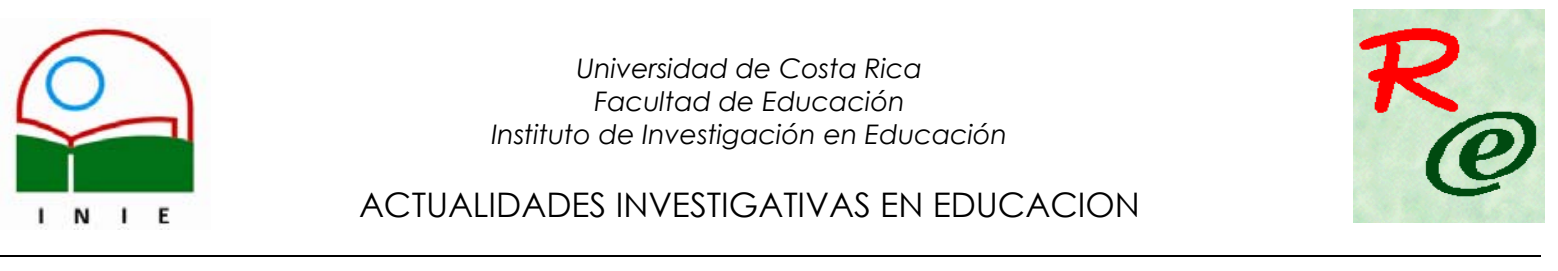

\title{
ANALYZING A PROBLEM-SOLUTION PATTERN IN THE TRANSCRIPTION OF A CONVERSATION: SUGGESTIONS FOR THE EFL CLASSROOM
}

\author{
César Alberto Navas Brenes ${ }^{1}$
}

\begin{abstract}
This paper analyzes a problem-solution pattern shown in the transcription of a conversation. This analysis is based on a conversation that has been elicited from three native speakers of English. These speakers were given a topic that dealt with the problem of children being constantly exposed to violent video games. As a result, the writer recorded an oral text that contains several elements related to a problem-solution pattern such as the main issue, opinions, personal examples, possible solutions, and the evaluation of these solutions. The writer analyzed this pattern in terms of discourse analysis using idea units from the transcription. Moreover, the writer will point out how appropriate this transcription is for preparing teaching tasks for the EFL classroom.
\end{abstract}

Key words: DISCOURSE ANALYSIS/ ANALYSIS OF ORAL TEXTS/ PROBLEM-SOLUTION PATTERNS/ TRANSCRIPTIONS OF ORAL TEXTS/

Resumen: Este artículo analiza el patrón estructural de la solución de un problema evidente en la transcripción de una conversación. El análisis está basado en un diálogo obtenido de tres hablantes nativos de la lengua inglesa. El autor suministró a dichas personas un tema relacionado con el problema de la exposición de niños al contenido violento de los juegos de video. Como resultado, se obtuvo una grabación del texto oral que contiene varios elementos relacionados con el patrón estructural de la solución de un problema. Algunos de estos elementos son el problema principal, opiniones, ejemplos personales, soluciones viables al problema, y la evaluación de dichas soluciones. El autor analizó algunas líneas de la transcripción con la ayuda de algunos conceptos relacionados con el análisis del discurso. Cabe destacar que el uso de tales transcripciones es muy apropiado en la preparación de actividades para una clase de inglés como lengua extranjera.

Palabras clave: ANÁLISIS DEL DISCURSO/ ANÁLISIS DE TEXTOS ORALES/ PATRÓN ESTRUCTURAL DE LA SOLUCIÓN DE UN PROBLEMA/ TRANSCRIPCIONES DE TEXTOS ORALES/

\section{INTRODUCTION}

There are several ways in which human beings internalize and transmit ideas or events before coming up with verbal messages. These verbal utterances cannot be expressed without following certain types of organization. As Chomsky (1995, cited in Lapaire and Rotgé) explains "the utterances we hear or read are not preassembled constructions that come of nowhere, but are stretches of discourse that are generated in a given speech

\footnotetext{
Magíster en la Enseñanza del Inglés como Lengua

Extranjera, Universidad de Costa Rica; Bachiller en Inglés, Universidad Internacional de las Américas. Profesor de la Escuela de Lenguas Modernas de la Universidad de Costa Rica. Tiene
}

Correo electrónico: cesar navas@racsa.co.cr

Artículo recibido: 11 de octubre, 2005

Aprobado: 21 de noviembre, 2005 
situation with specific communicative aims (1995, p. 53)." In other words, in order for the receiver of a verbal message to comprehend the meaning of what the sender is producing, the latter must follow certain patterns of organization according to situational contexts and what the sender $s$ trying to communicate. Thus, if someone tells a narration in a highly disorganized way without presenting key events or sections of the story in a given chronological order, the receiver will encounter more difficulty to comprehend meaning. This is a key characteristic of spoken language. Even though "discourse, then, does not consist simply of a string of grammatically well-formed utterances or structures," coherence, cohesion and unity will certainly play a major role in this kind of conversational pattern (Coulthard, 1977 , p. 7). Therefore, by respecting the segments of a certain pattern of organization, the receiver will certainly decode the message of what he or she is being said according to the connections within the structure of the text.

Before defining what a problem-solution pattern is, it is essential to refer to the meaning of clause relations. According to Winter (cited in Lapaire and Rotgé) "a clause relation is the cognitive process whereby the reader interprets the meaning of a clause, sentence, or group of sentences in the context of one or more preceding clauses, sentences, or groups of sentences in the same text" (1997, p. 54). This means that clause relations are responsible for building up "macro patterns of organization" (Lepaire and Rotgé, edited by McCarthy and Carter, 1994). The receiver of a verbal message interprets meaning by making sense of a logical sequence of contextualized events or details. Although there are different types of patterns of text organization, this paper is going to focus on the problem-solution pattern of a conversation between three native speakers of English. Furthermore, it is also important to explain what conversational discourse means. Richards et al. (1992, p. 85) say that

conversational analysis is the analysis of natural conversation in order to discover what the linguistic characteristics of conversation are and how conversation is used in real life. Conversational analysis includes the study of: (a) how speakers decide when to speak during a conversation (i.e. rules of turn-taking); (b) how the sentences of two or more speakers are related; (c) the different functions that conversation is used for (for example to establish roles, and to communicate politeness and intimacy).

Once a transcript of a recording has been prepared, the discourse analyst can observe how these elements of spoken language interact among them. In terms of turn-taking, the three participants maintain a respectful position throughout the conversation that will be analyzed in this paper; for this reason, there are few instances of interruptions. They usually 
wait until one speaker has finished his or her contribution to the conversation before giving an opinion.

A problem-solution pattern consists of a series of basic elements that constitute its structure. These are (1) the main problem or issue, (2) responses or reactions, (3) possible solutions, and (4) the evaluation of those possible solutions. It is crucial to mention that some of these elements may be more developed than others, and they may contain more idea units or centers of interest. Moreover, some optional elements might also be included in the text such as personal anecdotes, background information, examples, or possible causes and consequences that surround the main problem. In addition, one source expands on the basic features of a problem-solution pattern:

In the problem-solution pattern, the key element that marks the completion of the pattern

is a positive evaluation of at least one of the possible solutions offered. If positive evaluation for any particular solution is withheld, the writer normally turns to consider other possible solutions. A text which ends with no possible solution offered leaves the reader with a feeling of unease; no one likes to think problems are unsolved. [...] Most problem-solution patterns will end with a preferred solution, but may have stages in between where solutions are rejected, or partially accepted, creating more complex patterns. (Lapaire and Rotgé, edited by McCarthy and Carter, 1994)

Furthermore, this kind of conversational pattern must have, of course, a main problem or issue which is going to be discussed or developed throughout the oral text. Thus, participants of a group discussion are expected to come up with at least one solution to the issue they are dealing with. In some cases, this problem may be followed by a response; that is, the element that proposes an alternative to solve the issue, but which is not a solution itself. Afterwards, this pattern is formed by possible solutions and explanations in order to finish the conversation. Finally, an evaluation marks the end of the pattern.

\section{Methodology}

\subsection{Subjects}

In order to find a suitable text with this particular pattern, the writer had to look for a sample of spoken language organized as a conversation or group discussion in which two or three speakers participate. This paper is based on a real-life conversation between three native speakers of English. The subjects who participated in the recording were three Baptist missionaries who live in San Francisco de Dos Rios, San Jose. For research purposes, the 
first speaker has been labeled as $\langle\mathbf{S 0 1} \mathbf{}$. He is a 41 year-old missionary who comes from Alabama, US. The second participant (<S02 $>$ ) is a female missionary. She is approximately 40 years old. She is originally from Arkansas. Finally, the last speaker $(<\mathbf{S 0 3}>)$ is a 40 yearold missionary who comes from Texas. He was the dominant speaker throughout the conversation because he definitely added a large number of idea units to the oral text. In order to elicit a text that includes a problem-solution pattern, the writer looked for a controversial topic to be discussed that could promote participation and interaction among participants. This topic dealt with the influence that violent video games may have on children. It was interesting to know what these participants, who have a strong religious background, think about this topic.

There are some reasons why preparing a transcript of long conversations is a difficult task. First, discourse analysts should determine where centers of interest are located. After this, all idea units or units of thought have to be identified and separated. This challenge does not necessarily take place in written language. As a matter of fact, McCarthy $(1994$, p. 25) explains that

With written texts, some of the problems associated with spoken transcripts are absent: we do not have to contend with people all speaking at once, the writer has usually had time to think about what to say and how to say it, and the sentences are usually well formed in a way that the utterances of natural, spontaneous talk are not.

Linguists have to separate idea units (short pieces of spoken text) taking into account the notions of coordinators, subordinators, intonation, topics of centers of interest, pauses, as well as discourse markers or fillers. Moreover, certain vocabulary items, for example, limit the way idea units are divided. The word well, for instance, usually indicates that a speaker is introducing an opinion, so it limits one unit of thought that may probably begin a new center of interest. The transcription used in this paper (see the Appendix section) has been prepared according to the notions given by Chafe (1980) to identify and break up long pieces of spoken language.

\section{ANALYSIS OF THE CONVERSATION}

Transcribing a conversation is a time-consuming task. The level of difficulty increases due to the number of speakers who participate in the group discussion as well as the interruptions that occur throughout the conversation. In this case, the writer elicited only a short segment of a very extensive conversation. He chose this portion because it contains 
the most illustrative and relevant details of a problem-solution pattern. The center of interest below contains the first part of the oral text. The first element of the problem-solution pattern is the main issue or problem which appears in most cases at the beginning of this conversation. Speaker $<$ S01 $>$ brings it up to the conversation. In excerpt (a), the speaker not only explicitly introduces the topic in lines 1-2 by asking a direct question, but also provides an example in lines 3-8 that illustrates how serious this problem might eventually become:

(a) (1) < S01> Video games .. how they influence kids?

$(2)<$ S01 $>$ Well I think that video games are very addictive,

(3) $<$ S01> l've discovered .. ah with my youth

(4) $<$ S01> they start playing video games,

(5) $<$ S01 $>$ and they become addicted to a certain game,

(6) $<$ S01> and they play it all the time,

(7) $<$ S01> and it seems that the more violent the game is,

(8) $<$ S01 $>$ the more likely they are gonna get addicted to it

(9) <S02> I can't.. I don't play violent games,

In lines (7-8) the speaker provides additional information to refer to the main issue. Therefore, this center of interest is characterized by the problem found in line 2 (as well as lines 7 and 8), and some further background in lines 3-9.

The following center of interest is composed by a personal example or anecdote given by the second speaker. It is interesting to point out that although this example is closely related to the topic under discussion, it is the third participant who goes back to the original problem which is the influence that violent video games may have on children, and not exactly the effect of video games in general. This takes places in lines 14 and 16 . Consider the following part of the transcription:

(b) (9) <S02> I can't .. I don't play violent games,

(10) $<$ S02> I just play games on computer,

(11) < S02> I always say when I win I'll quit,

(12) $<$ S02> but then no I can win again no I can win!

(13) < S02> so I just keep going and going.

(14) < S03> But what about the violent games?

(15) $<$ S03> though I mean you will not play them,

$(16)<$ S03 $>$ but do you think the influence that that has? 
This group of idea units has two speakers who did not interrupt each other. However, one characteristic of the third speaker is that he has a dominant role throughout the conversation. Notice how in lines 14-16 he re-states the main issue before coming up with a possible consequence due to that problem. Likewise, the second speaker also provides a second effect which reinforces what has already been said so far. It is worthy of attention that in line 27 (center of interest c), the female speaker begins her content with the words "well the Bible says..." This might be considered a common opening or expression some religious people (in this case a Baptist missionary) use when introducing certain comments or ideas. This is illustrated in the following excerpt:

(c) (23) <S03> and that's the danger of video games,

(24) $<$ S03> because if the mind sees this (sees this) (sees this),

(25) $<$ S03> and then there is no separation

(26) <S03> in the child's mind between reality .. and imagination.

$(27)<$ S02 $>$ Well the Bible says that what you put into your mind is what comes out also,

(28) $<$ S02 $>$ [<S03> hmm...mmm] so if you feed it with violence,

$(29)<$ S02> then violence is then manifested itself in your own.

The main problem of this conversation has been stated twice, and a couple of consequences have been proposed; however, nobody has given any solution yet. Furthermore, the main issue has been brought up to the conversation once again; in this case by the first speaker. The following center of interest includes this point:

(d) $(42)<$ S01 $>$ the big question is:

(43) $<$ S01> how to help somebody see the danger that .. the ins..

(44) $<$ S01 $>$ the fact that they are becoming desensitized to those sort of things,

(45) $<$ S01> the danger it can be really.

One of the significant features of the problem-solution pattern has to do with the fact that it is formed by a series of supporting elements that will add more material to the topic under discussion. For example, in line 44 the speaker contributes with another consequence of having people playing games; that is, that they become desensitized due to the amount of violence they are watching. This speaker, as well as the writer, expected an answer which was given by the third member. As has been indicated before, possible solutions are 
expected when referring to a problem; that is, in a group discussion it is likely to have at least one solution. For this reason, from line 50 to 52 , the third speaker says that one possible solution is to keep children apart from violent video games. This person even numbers his solution. At the same time, in line 53 , he gives a possible cause. He says that children use this type of games because they do have lots of leisure time. Line 53, on the other hand, is another problem itself that might lead to a whole different conversation. A possible solution and the cause regarding the main problem can be seen in the following portion of the script:

(e) $\quad(50)<$ S03 $>$ well number one we have to get them away from the game

(51) < S03> you know we have to get them away from that minds

$(52)<$ S03 $>$ that (that) sitting around playing video games or (or) whatever you know.

(53) < S03> In our society today kids have a ton of free time,

The next element of a problem-solution pattern is the evaluation. It usually follows one of the possible solutions proposed in order to solve the issue. If we consider as a solution what the third speaker has said about taking kids apart from violent video games; then the evaluative segments of the text include the cause of the problem (line 53), and his personal example about this cause in lines 55-63. Consider the following excerpt:

(f) $\quad(55)<$ S03> I mean .. when I was a kid,

(56) < S03> everything that we did you know after school was you know either work on the farm or play sports you know.

$(57)<$ S03 $>$ those were .. yeah we either played sports,

$(58)<$ S03 $>$ there were no video games,

(59) $<$ S03> there was not TV,

$(60)<$ S03> there were not that stuff you know,

(61) < $03>$ we didn't have those influences you know,

(62) < S03> but you know I mean I can see how addictive it is,

(63) $<$ S03> but you know in the same way for me sports was that way,

In this complete center of interest, the speaker refers to his own experience when he was a kid. He says that during his childhood, kids did not have the possibility of playing video games. On the contrary, he either worked or played outdoor sports. In addition, there were no video games that made kids change their behavior and become aggressive or violent. The participants give lots of importance to the role parents should have in order to monitor the 
content of these games. Although the solution goes from line 131 to 144 , the neighboring idea units serve as the evaluative element of that solution. This center of interest illustrates this point:

(g) $\quad(131)<$ S02> ...Well one thing that parents can do is to be the parents.

$(132)<$ S02> The money is the parents' money.

(133) $<$ S03> That's right!

(134) < $02>$ and they can keep from buying things,

(135) $<$ S02> yeah somebody

(136) $<$ S02> and they can help the children,

$(137)<$ S02> they can speak to the children,

$(138)<$ S02> and help them understand...

(139) <S02> how to make right choices,

$(140)<$ S02> so they can guide the child,

(141) < $02>$ which is actually the child's choice,

$(142)<$ S02> but the parents guide them in such a way

$(143)<$ S02 $>$ that the child makes the right choice

(144) $<$ S02> and not the wrong one.

Lines 131-134 contain the main solution while the rest of the conversation presents the evaluation of that solution. All the rest of the ideas contain the meaning of what solution \#2 is all about.

Vocabulary items play a very important role in the development of every type of text organization. As MacCarthy and Carter indicate (1994, p. 105), the type of vocabulary people commonly use when referring to a problem-solution pattern "signals its structure in advance." Although there are certain words that explicitly determine how this particular pattern is being developed (e.g., problem, issue, or solution), only two clear examples were found throughout the conversation. The writer collected the following utterances: the big question is (line 42), and issue (line 47). However, it is interesting to see the number of discourse markers (well, you know, I mean, yeah, or so) used in the text. As a matter of fact, the third speaker used the phrase you know more than the other two speakers. This marker appeared 18 times. The word well was used 4 times. While the meaning and use of you know can vary among idea units, the use of well seems to be more consistent. Consider these idea units:

(2) <S01> Well I think that video games are very addictive,

(27) $<$ S02> Well the Bible says that what you put into your mind is what comes 
out also,

(50) <S03> well number one we have to get them away from the game

$(131)<$ S02 $>$...Well one thing that parents can do is to be the parents.

In these cases, the marker well signals the introduction of an opinion. On the other hand, the marker I mean (which was used only in 3 instances) is more likely to signal clarification and addition of supporting information. This can be seen in these examples:

(15) $<$ S03 $>$ though I mean you will not play them,

(55) $<$ S03> I mean .. when I was a kid,

(62) < S03> but you know I mean I can see how addictive it is,

Different lexical items (summarized in Section 2.1), therefore, have a clear role in the development of discourse, especially in constructing large types of text organizations.

By looking at this text in terms of a problem-solution pattern, there are several elements that provide additional material to this type of text organization. Figure 1 is an attempt to summarize the most important elements of this pattern. It includes the lines of idea units within the text. To sum up, this pattern consists of an introduction to the main problem (lines 1-8) that leads to the corpus of the entire conversation. This problem is supported by a personal example (lines 9-13). Once the main problem is left apart, the issue is again brought up to the conversation (lines 14-16). The speaker asks the other two participants direct questions. Moreover, two relevant consequences are included (lines 23-26, and 4245). After two direct questions are given (lines 30-31, and 42-45), the first solution is presented (lines 50-52). Once this solution is offered, more elements are added to this pattern of organization, for instance: one possible cause (line 53), one personal example (lines 55-61), and two additional examples. Then, a second solution appears in lines 131132. Then, it is followed by an evaluation (133-144). All these elements construct the problem-solution pattern found in the transcription of this conversation elicited from this group of native speakers of English. 


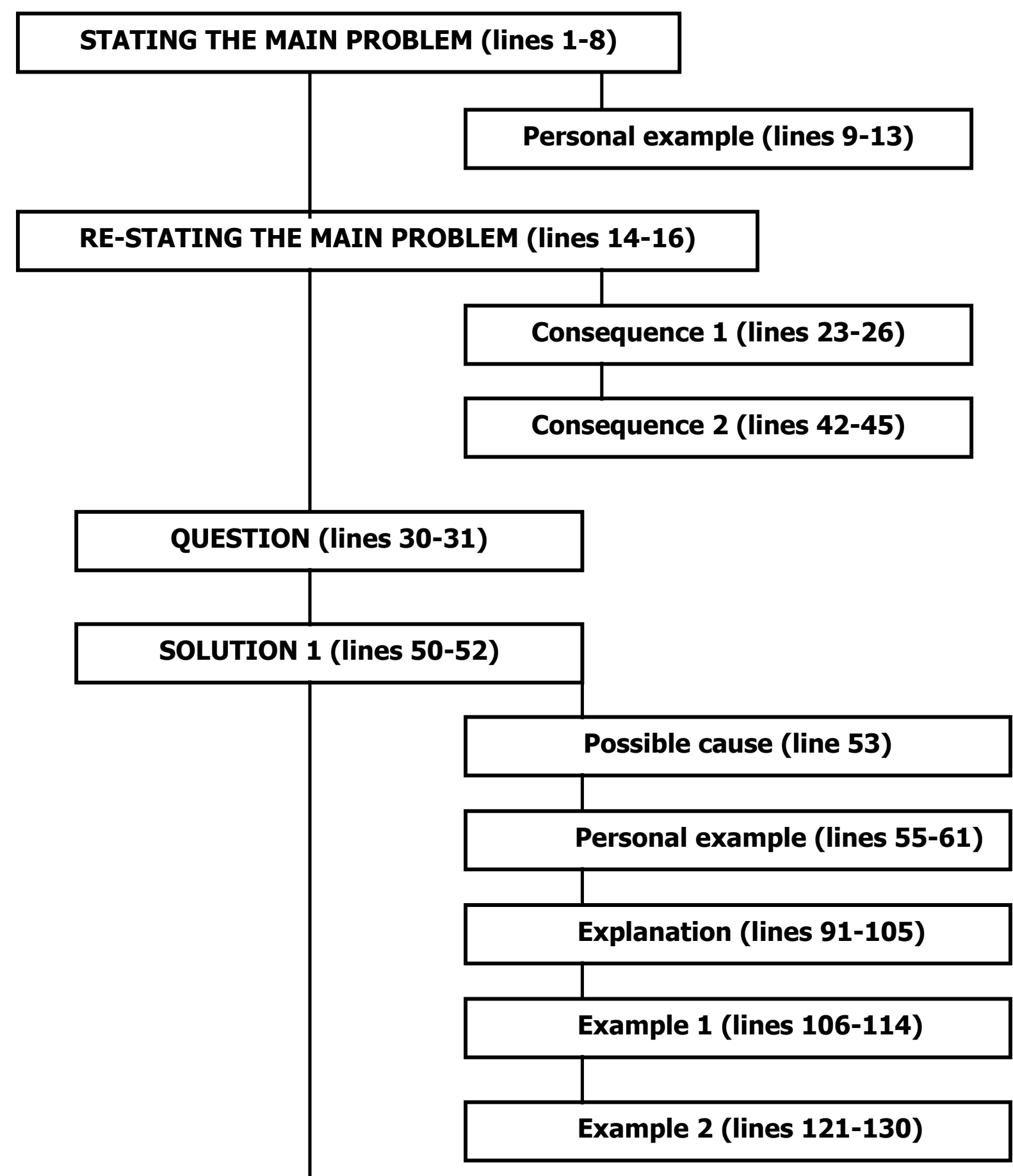

\section{SOLUTION 2 (lines 131-132)}

Figure 1: Text Frame

Evaluation (lines 133-144) 


\subsection{Summary of Details of the Spoken Mode}

1. (24) $<\mathrm{S} 03>$ because if the mind sees this (sees this) (sees this),

(12) <S02> but then no I can win again no I can win!

(124) < S02> and was like ohh! This hurts! (this hurts!) you know,

Repetition of words or phrases is a common feature of the spoken language.

2. (19) <S03> It's your hand that commits the crime?

(20) $<$ S03> or your leg that commits the crime?

The speaker uses affirmative statements that function as questions. Intonation plays a crucial role to interpret the speaker's intention.

(1) <S01> Video games .. how they influence kids?

In line 1, the speakers introduces the main problem. The auxiliary do is not used.

3. $(28)<\mathrm{S} 02>[<\mathrm{S} 03>\mathrm{hmm} . . . \mathrm{mmm}]$ so if you feed it with violence,

In this case, speaker 03 agrees with the idea given by another participant without uttering words. One source notes that "in the early stages of the discussion other speakers are reluctant to intervene with comments of their own; however, verbal and non-verbal backchanneling takes place to give support to the speakers (McCarthy and Carter, 1997)." This is reinforced by body language such as nodding the head.

4. (30) <S01> how do you .. [???] how do you help a person who is addicted to violent.. eh.. video games.. whatever..

(92) <S03> whatever you know we differentiate [???]

(95) < $01>$ and starts destroying the enemy or whatever,

By using the word whatever, the speaker does not want to specify his content.

5. (34) $<$ S01> and things like that ..

$(60)<$ S03> there were not that stuff you know, 
Regarding the use of phrases like "things like that" or "that stuff," the source mentioned before explains that

...speakers select vague language as here so that they do not have to specify precise examples-a procedure which would be necessary in more formal discussion in most academic contexts but which is not a prerequisite for informal discussion. In informal discussion among equals speakers deliberately do not want to sound too authoritative. (1997)

6. (56) <S03> everything that we did you know after school was you know either work on the farm or play sports you know.

(61) $<$ S03> we didn't have those influences you know,

(62) $<$ S03> but you know I mean I can see how addictive it is,

(81) <S03> and we need other people to help us you know,

The use-or sometimes the overuse-of the formulaic expressions "you know" and "I mean" can have a high level of frequency in the spoken mode.

7. $(44)<S 01>$ the fact that they are becoming desensitized to those sort of things,

The participant does not want to exemplify or extend his or her content. McCarthy and Carter wrote that similar phrases "occur commonly when a speaker expresses an opinion about somebody or something" (1997).

8. (36) <S01> l'm not gonna out and kill somebody .. in their responses

(37) $<$ S01> I'm not gonna do those things [???]

(40) $<$ S01> It's not gonna affect me in that way

There is an extensive use of reductions (as well as repetitions) in the spoken mode.

9. $(50)<S 03>$ well number one we have to get them away from the game $(131)<$ S02 $>$...Well one thing that parents can do is to be the parents.

The word well usually introduces a new opinion or comment related to the main problem. 
10. (107) <S03> but l've never seen one of those games that say you've died you're dead.

(108) <S01> but if you died you (you)

$(109)<503>$

you [???] just go back [???] and you go again exactly.

(110) < $01>$ Yeah yeah my son has this little pocket game boy,

Interruptions can take place at any time. They certainly increase the difficulty of transcribing a conversation in which many speakers participate. Interruptions should be indicated in the transcription of oral texts. In this conversation, participants wait for an opportunity to speak; they do not interrupt regularly.

11. $(123)<S 02>$ but he got shot,

(124) <S02> and was like ohh! This hurts! (this hurts!) you know,

$(125)<$ S02> and he didn't have any concept,

Coordinating conjunctions such as and or but are highly used. They almost always limit idea units that relate to the topic of each center of interest.

\section{PEDAGOGICAL IMPLICATIONS FOR THE ESL CLASSROOM}

At this point, an important question takes place: what is the purpose of analyzing a problem-solution pattern in the EFL classroom? First of all, using transcriptions of oral texts give learners the opportunity to observe how spoken language works. Students, therefore, are exposed to a great variety of features of spontaneous and natural speech. Unfortunately some language learners deal with textbook language rather than everyday speech used in real-life situations. For this reason, the transcription of this conversation (as well as the tape) is suitable for preparing different types of activities. These are some suggestions that language teachers can implement in their courses:

a- students at a low level can read the transcript; then they come up with the main idea or problem of the conversation (or specific centers of interest) and discuss it

b- intermediate students can reflect on the use of particular discourse elements such as the purpose of using phrases such as you know, I mean, so, sort of, stuff like that, things like that, or so 
c- they might also look for personal examples or anecdotes throughout the text which are related to the main problem (scanning)

d- students read the conversation and relate the content of the conversation to their personal experience regarding violent video games

e- advanced learners can complete parts of a text frame similar to the one shown before

f- students may fill in the blanks with some idea units

g- learners can note down the main idea of particular centers of interests (groups of idea units that contain one topic)

h- teachers can draw attention to the use of discourse markers or fillers as well as idiomatic expressions

i- after students have analyzed the script, they can participate in their own group discussion about violent video games. Learners can record the conversation and analyze their discussion

j- learners can also prepare a summary based on the content of the discussion

k- teachers can make students explain whether or not the solutions are feasible or realistic (additional solutions can be given)

I- students can also answer information questions based on the content of the transcript

$\mathbf{m}$ - in relation to listening comprehension, students might listen to specific information such as examples, causes, anecdotes, or consequences of the main problem. Brief notes can be taken.

Moreover, students can also get acquainted with characteristics of English pronunciation if they use transcripts of conversation. In fact, transcriptions of oral texts can also help students focus on the supra-segmental features of language. Willis (1996) highlights the importance of analyzing scripts in the ESL classroom and indicates that

Phonology is another area worthy of analysis, and working from recording and transcripts can be invaluable. Learners need practice in identifying the main-messagebearing words in the flow of speech. This involves recognizing how spoken language is chunked, (each chunk is known as a tone unit), and hearing which word within each chunk (or tone unit) carries the main stress. This stress word, which usually has a falling tone $\rangle$ or a fall-rise tone $r$, will be the main message-bearing word, and the key to understanding the meaning of that chunk. So, instead of listening for sentences, learners should get used to listening for tone units and stressed words. If they do this, they will be more able to cope with the flow of speech. (cited in Willis, p. 109) 
Teachers can easily explain how people create a mental framework to express their thoughts into idea units; that is, the way in which people divide their verbal message into short ideas or groups of idea units that deal with a single topic. This is a major difference between the spoken and written mode (especially in academic writing). Furthermore, language instructors might also draw attention to intonation, stress, and rhythm. Most of the time, intonation (as well as connecting words) is a key tool to identify how idea units are separated. By doing so, students will have the opportunity to raise awareness in order to observe how connected speech works in a real-life situation.

In addition, one advantage of having low- intermediate students answering content questions relies on a practical consideration. If they have to answer a questionnaire using a reading text or article from a magazine or newspaper, some students can probably copy entire sentences that include that information. On the other hand, with the use of a transcript, they have to process meaning and write well-structured sentences based on idea units of different centers of interest. That is, they have to change ideas from the oral mode to the written one.

\section{CONCLUSION}

By using transcripts of conversations, language teachers and students will certainly learn more about the language in natural contexts. Although preparing transcripts is time consuming for instructors, they should reflect upon the benefits their students will certainly obtain from analyzing scripts. Students will feel highly motivated and interested in observing how spoken language functions in spontaneous contexts.

\section{REFERENCES}

Carter, R. and McCarthy, M. (1997). Exploring Spoken English. Cambridge: Cambridge University Press.

Chafe, L. W. (ed.) (1980). The Pear Stories: Cognitive, Cultural and Linguistic Aspects of Narrative Production. Norwood, N.J.: Ablex Publishing Corp.

Coulthard, R. M. (1985). An Introduction to Discourse Analysis. London: Longman.

McCarthy, M. J. (1994). Discourse Analysis for Language Teachers. Cambridge: Cambridge University Press.

McCarthy, M. and Carter, R. (1994). Language as Discourse: Perspectives for Language Teaching. London: Longman. 
Richards, J., Platt, J. \& Platt, H. (1992). Dictionary of Language Teaching and Applied Linguistics. London: Longman.

Willis, Jane. (1996). A Framework for Task-Based Learning. London: Addison-Wesley Longman Ltd. 


\section{APPENDIX TRANSCRIPT OF THE CONVERSATION}

(1) <S01> Video games .. how they influence kids?

(2) $<$ S01 > Well I think that video games are very addictive,

(3) <S01> l've discovered .. ah with my youth

(4) $<$ S01> they start playing video games,

(5) $<$ S01> and they become addicted to a certain game,

(6) $<$ S01> and they play it all the time,

(7) $<$ S01> and it seems that the more violent the game is,

(8) $<$ S01 > the more likely they are gonna get addicted to it

(9) <S02> I can't.. I don't play violent games,

(10) <S02> I just play games on computer,

(11) < S02> I always say when I win I'll quit,

(12) <S02> but then no I can win again no I can win!

(13) < S02> so I just keep going and going.

$(14)<$ S03 $>$ But what about the violent games?

(15) $<$ S03> though I mean you will no play them,

(16) $<$ S03 $>$ but do you think the influence that that has?

(17) $<$ S03> .. ah what part .. of the .. body is (is) the most important part

$(18)<$ S03> when it comes to .. actually committing the crime?

(19) <S03> It's your hand that commits the crime?

(20) $<\mathbf{S 0 3}>$ or your leg that commits the crime?

(21) $<$ S03> isn't it your soul

(22) <S03> your mind that is influenced,

(23) $<$ S03> and that's the danger of video games,

(24) <S03> because if the mind sees this (sees this) (sees this),

(25) $<$ S03 $>$ and then there is no separation

(26) $<$ S03 $>$ in the child's mind between reality .. and imagination.

$(27)<$ S02> Well the Bible says that what you put into your mind is what comes out also,

(28) $<\mathrm{S} 02>$ [ $<\mathrm{S} 03>\mathrm{hmm}$... $\mathrm{mmm}$ ] so if you feed it with violence,

(29) $<$ S02> then violence is then manifested itself in your own. 
[Short pause 05:03 seconds]

(30) < S01> how do you .. [???] how do you help a person who is addicted to violent.. eh.. video games.. whatever..

(31) < $01>$ How a person get out of that?

(32) < S01> because l've had (I've had) kids that l've worked with

(33) $<$ S01> that they were very much in the violent games involved .. movies

(34) $<$ S01> and things like that..

(35) < $01>$ that didn't see anything wrong with it .. you know

(36) < S01> I'm not gonna out and kill somebody .. in their responses

(37) < $01>$ I'm not gonna do those things [???]

(38) $<$ S01> I'm not the kind of person

(39) < $01>$ who says I'm gonna kill somebody

(40) < S01> It's not gonna affect me in that way

(41) <S01> and obviously it doesn't take some people that way .. and you know,

$(42)<$ S01> the big question is:

(43) $<$ S01> how to help somebody see the danger that .. the ins..

(44) $<$ S01 $>$ the fact that they are becoming desensitized to those sort of things,

(45) $<$ S01> the danger it can be really.

[Long pause 06:81 seconds]

(46) $<$ S03 $>$ oh, one of the things that is about (about)

$(47)<$ S03 $>$ the issue that (speaker $<$ S01 $>$ ) is talking about right now

$(48)<$ S03> is that so many kids [???] it's not really all that bad,

(49) < S03> how can you help them?

$(50)<$ S03> well number one we have to get them away from the game

(51) < S03> you know we have to get them away from that minds

(52) $<$ S03> that (that) sitting around playing video games or (or) whatever you know.

(53) < S03> Our society today kids have a ton of free time,

$(54)<$ S03 $>$ and it (and) it seems that watch TV or play video games or you know,

(55) <S03> I mean .. when I was a kid,

(56) $<$ S03> everything that we did you know after school was you know either work on the farm or play sports you know.

(57) < S03> those were .. yeah we either played sports,

(58) $<$ S03> there were no video games, 
(59) $<$ S03> there was not TV,

$(60)<$ S03 $>$ there were not that stuff you know,

(61) <S03> we didn't have those influences you know,

(62) <S03> but you know I mean I can see how addictive it is,

(63) <S03> but you know in the same way for me sports was that way,

(64) <S03> but sports [???] team work

(65) <S03> [???] you help each other

(66) $<$ S03> you think of the game .. you didn't get your .. you were ..

(67) $<$ S03> those guys that were your enemies

(68) $<$ S03> even though you played against them

(69) < S03> because next week they may be the guys on your team, you know,

$(70)<$ S03> so it was you know there is (there is) such a one side that look

(71) $<$ S03> when you look at these games,

(72) $<$ S03 $>$ if you pick a side,

(73) $<$ S03> that's a side for a life you know

(74) $<$ S03> and I'm gonna shoot

(75) <S03> and kill everybody who is not on my side,

(76) < S03> and I'm gonna destroy everyone who is not on my side,

(77) $<$ S03> and that's one of the biggest dangers of this,

(78) $<$ S03> they don't see the importance of other people,

(79) $<$ S03> how we can't do it alone,

(80) $<$ S03> it's impossible to do anything alone,

(81) <S03> and we need other people to help us you know,

(82) < S03> because I'm not a doctor you know,

(83) < S03> when I broke my knee

(84) < $03>$ I've had a doctor to repair me,

(85) <S03> I'm not a lawyer I'm not

(86) $<$ S03> there are so many things that I cannot do,

(87) < S03> I'm just one little insignificant in this [???] wild,

$(88)<$ S03 > but everyone of us is needed to make society work,

(89) $<$ S03> and if we go out there,

(90) $<$ S03> and say so and so is my enemy

$(91)<$ S03> because if it looks this way acts that way talks that language

(92) < $03>$ whatever you know we differentiate [???] 
(93) < S03> then obviously our society is gonna fall apart

(94) < $01>$ When the a person is involved in these games,

(95) < $01>$ and starts destroying the enemy or whatever,

(96) $<$ S01> then shoot back

$(97)<$ S01 $>$ one of the things is that he never gets shot dead

(98) $<$ S03> that's right!

$(99)<$ S03> and they learn that.

(100) <S03> It's like I can go out and kill all those people,

(101) <S03> and that's not gonna happen to me [???]

$(102)<$ S03 $>$ and one of the things about those games you know

$(103)<$ S03> is you may (you may) you can go around and kill those people,

(104) <S03> but you'll never die

(105) <S03> you just lose

(106) <S03> It's like saying you lose

$(107)<$ S03> but l've never seen one of those games that say you've died you're dead.

$(108)<$ S01> but if you died you (you)

$(109)<$ S03>

you [???] just go back [???] and you go again exactly.

(110) < S01> Yeah yeah my son has this little pocket game boy,

(111) $<$ S01> it has a game in it,

(112) < $01>$ [???] he got mad because somebody talked to him

(113) < S01> you made me die you know I mean

(114) < S01> and he had to start it all over ..

(115) < S01> I couldn't get upset with him

$(116)<$ S01 $>$ because he is so (is so) involved in that game

$(117)<$ S01> and he gets mad if someone causes him death.

$(118)<$ S02> They don't understand what death is and what pain is

(119) $<$ S02> because they don't feel it,

(120) $<$ S02> they're just doing it [speaker laughs] to somebody else.

(121) < S02> I saw it was on a TV show where I saw

(122) < $02>$ how a guy that has been shooting people,

(123) $<$ S02> but he got shot,

(124) < $02>$ and was like ohh! This hurts! (this hurts!) you know, 
(125) < S02> and he didn't have any concept,

(126) < S02> because he never felt it,

(127) < $02>$ when he do it to somebody else,

(128) <S02> because he'd never got it,

(129) $<$ S02> but when he actually received it

$(130)<$ S02> it was like it was something different...

$(131)<$ S02 $>$...Well one thing that parents can do is to be the parents.

(132) <S02> The money is the parents' money.

(133) <S03> That's right!

(134) <S02> and they can keep from buying things,

(135) < $02>$ yeah somebody

(136) <S02> and they can help the children,

$(137)<$ S02> they can speak to the children,

(138) <S02> and help them understand...

(139) <S02> how to make right choices,

$(140)<$ S02> so they can guide the child,

$(141)<$ S02> which is actually the child's choice,

(142) $<$ S02> but the parents guide them in such a way

$(143)<S 02>$ that the child makes the right choice

$(144)<$ S02> and not the wrong one.

(145) <S03> Exactly. 